IMECE2006-14526

\title{
RESIDUAL STRESSES IN PASSENGER CAR WHEELS
}

\author{
Shuangqin Liu \\ Dept. of Mechanical Engineering \\ Tufts University \\ Medford, MA 02155 USA \\ shuangqin.liu@tufts.edu
}

\author{
Benjamin Perlman \\ Dept. of Mechanical Engineering \\ Tufts University \\ Medford, MA 02155 USA \\ bperlman@tufts.edu
}

\author{
Jeff Gordon \\ US DOT \\ Volpe Center \\ Cambridge, MA \\ gordonj@volpe.dot.gov
}

\begin{abstract}
Knowledge of the residual stress state in wheels resulting from manufacturing and subsequent service loading is useful for several practical reasons. The ability to estimate residual stress levels permits the tuning of manufacturing processes to control the magnitude and distribution of these stresses in new wheels in order to achieve safe performance in service. Similarly, understanding the redistribution of residual stresses following application of service loads (wheel/rail contact and thermal stresses) is crucial to avoid operating conditions which may lead to premature wheel failure.

Axisymmetric (2-dimensional) analyses are typically performed in order to conduct manufacturing process simulations since these processes affect the entire wheel in a circumferentially uniform sense.

Generally, analyses involving service loading have sought to identify the "shakedown state" at which the residual stress distribution stabilizes after some number of loading cycles. In order to properly account for service loads, 3-dimensional models are required since contact and brake shoe thermal loading are not axisymmetric. Since the as-manufactured residual stress distribution must be considered in a service loading simulation, 3-dimensional modeling of this process is required. This paper presents a preliminary comparison of 2and 3-dimensional modeling of the wheel heat treatment process. Except for the increased computational time required for the 3-dimensional analysis, the results agree favorably. The 3-dimensional model is used to simulate service loads involving wheel-rail contact loading representative of a typical passenger car. The model is exercised with a variety of material models for comparison with previous work. Results are presented for multiple loading scenarios and shakedown stress states are established for a range of applied loads.
\end{abstract}

\section{INTRODUCTION}

Residual stresses are important to understand in order to avoid operating conditions which may lead to development of adverse stresses which can cause premature wheel failure. Residual stresses in wheels originate during the manufacturing process and are subsequently modified when wheels are placed in service and subjected to repeated wheel/rail contact and thermal loading during on-tread friction braking. The manufacturing process generally leaves the wheel rim in a state of residual compression. This compression helps to resist wheel tread crack formation. Thermal loading from ontread friction braking has been demonstrated to cause rim stress reversal from compression to tension, leading to the development of wheel tread thermal cracking.

Early attempts to estimate residual stresses in wheels considered a combination analysis. Standard finite element techniques were applied to estimate the residual stresses due to the quenching and annealing portions of the manufacturing process [1, 2]. These stresses were then used as an initial condition for subsequent consideration of mechanical (wheel/rail contact) and thermal (from friction braking) stresses that were analyzed using a "shakedown" approach [1, 3]. The shakedown method purports to provide efficiency in that the stabilized residual stress distribution is achieved in a single step, without the need to consider the loading history cycle-by-cycle. The method, however, comprises several limitations, the most important of which is the elasticperfectly plastic material characterization.

More recent research has focused on the effect of brake shoe heating and the potential for rim stress reversal [4, 5]. This work was accomplished using an axisymmetric (2dimensional) representation of the wheel. This modeling assumption precludes realistic application of wheel/rail 
contact loads, since the earlier research demonstrated that thermal loading is the dominant service load.

A secondary goal of this work is to begin to formalize the procedures to be specified in a developing American Public Transit Association (APTA) wheel design standard. The new standard is under consideration as a replacement for the current Association of American Railroads (AAR) Standard S660. The S-660 standard specifies the conduct of specific finite element analyses using prescribed loading conditions. However, the loading specified in the S-660 standard is more relevant to freight than passenger applications. Specifically, the thermal loading requirement represents a drag-braking scenario, more common in freight than passenger operations. Further, the current S-660 has several shortcomings:

1. The analysis assumes fully elastic conditions.

2. There is no allowance for the existence of beneficial compressive residual stress that is imparted during manufacture.

3. The basis for approval is an empirical comparison. Approval for use of the wheel in service is granted following favorable comparison (by an independent third party) of results of this analysis with those in a database of previous analysis results for other wheels.

In order to develop a revised wheel qualification procedure, a methodology must be developed to overcome these limitations.

As described above, the bulk of previous work has focused on application of axisymmetric models to estimate residual stresses due to heat treatment and thermal loading from braking. Contact loads were not considered. To properly account for wheel/rail contact effects and represent braking more realistically, a three-dimensional model is necessary. Furthermore, in the spirit of developing a useful alternative wheel design standard, an integrated modeling approach is desired. An integrated model will overcome the first two limitations noted above. The remainder of this paper seeks to address these issues.

The revised wheel design standard is envisioned to be self-qualifying in that independent review of the results will not be required. Instead, application of a fatigue criterion is being considered whereby the adequacy of the wheel design can be demonstrated using the results of the prescribed analysis. This effort is described in a companion paper in these proceedings [6].

The context for the work reported here is an assessment of the importance of contact load effects to the design standard. Previous work, based on axisymmetric models, inherently limits such an examination [1,2]. Restrictions on the analysis technique imposed simplified representations of several important features. To account for the lateral movement of the wheel on the rail, equivalent Hertz contact loads were applied to a rectangular patch for only one (static) wheel load. In addition, the inelastic effects had to be represented as an Elastic, perfectly plastic material with carefully chosen flow stress levels.

For regions away from the tread surface, neglect of contact effects is well justified. In regions close to the surface, a more accurate representation of the influence of wheel-rail interaction could adjust or tune calculations based on braking loads alone.

This paper starts with a model of wheel manufacturing to establish the credibility of a three-dimensional model of a wheel. The same mesh is used to examine the influence of load and material parameters on the nature of the residual stress field in the wheel. These effects are examined as service conditions without pre-stress from manufacturing to ensure that the contact field is the sole influence. The depth of the compressive zone near the tread surface is the focus of the calculation.

\section{HEAT TREATMENT SIMULATION: COMPARISON OF 2D AND 3D MODEL RESULTS}

A 32-inch $(81 \mathrm{~cm})$ reverse dish passenger car wheel is chosen for the prototype analysis to allow comparison with previous results obtained using an axisymmetric model. The wheel is quenched from a uniform temperature of $1550{ }^{\circ} \mathrm{F}$ $\left(843^{\circ} \mathrm{C}\right)$. The wheel is then annealed at $925^{\circ} \mathrm{F}\left(496{ }^{\circ} \mathrm{C}\right)$ for approximately 4 hours. After annealing, the wheel is allowed to cool to room temperature. The analysis procedure follows that described in [1]. A complete description of the development of the three-dimensional heat treatment model presented here is described in [7]. Temperature-dependent thermomechanical material properties are used. The room temperature yield strength is $45 \mathrm{ksi}$ (310 MPa). Viscoelastic creep is accounted for using a user subroutine in ABAQUS [8]. Convective and radiative boundary conditions are applied to permit surface cooling during the simulations.

Two and three-dimensional models were constructed to compare results of the heat treatment simulation. The 2-D model is similar to that presented in [1-5] and comprises 1362 elements, as shown in Figure 1. Special care is taken in the construction of the three-dimensional model so that sufficient element density exists in the vicinity of the point of application of the contact loading.

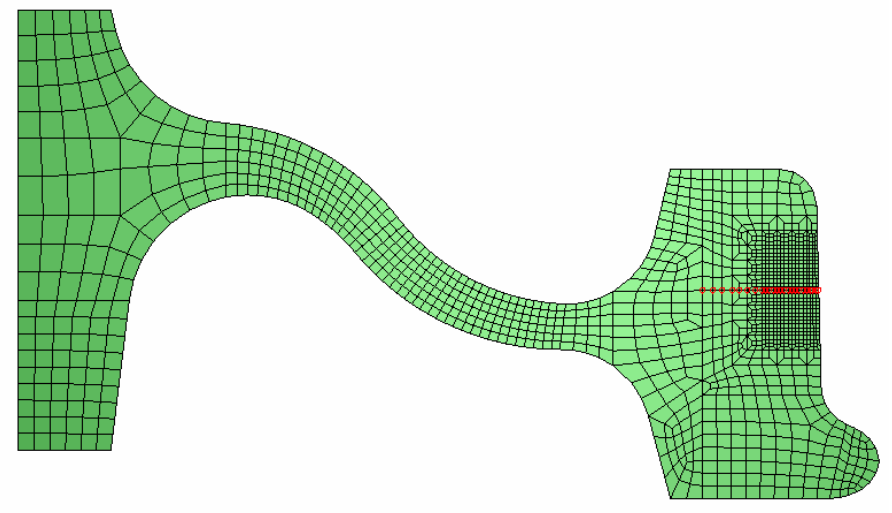

Figure 1. 2D axisymmetric model. 
The three-dimensional model is shown in Figure 2. It consists of approximately 53,000 8-node brick elements. The mesh is graded in the circumferential direction for computational efficiency.

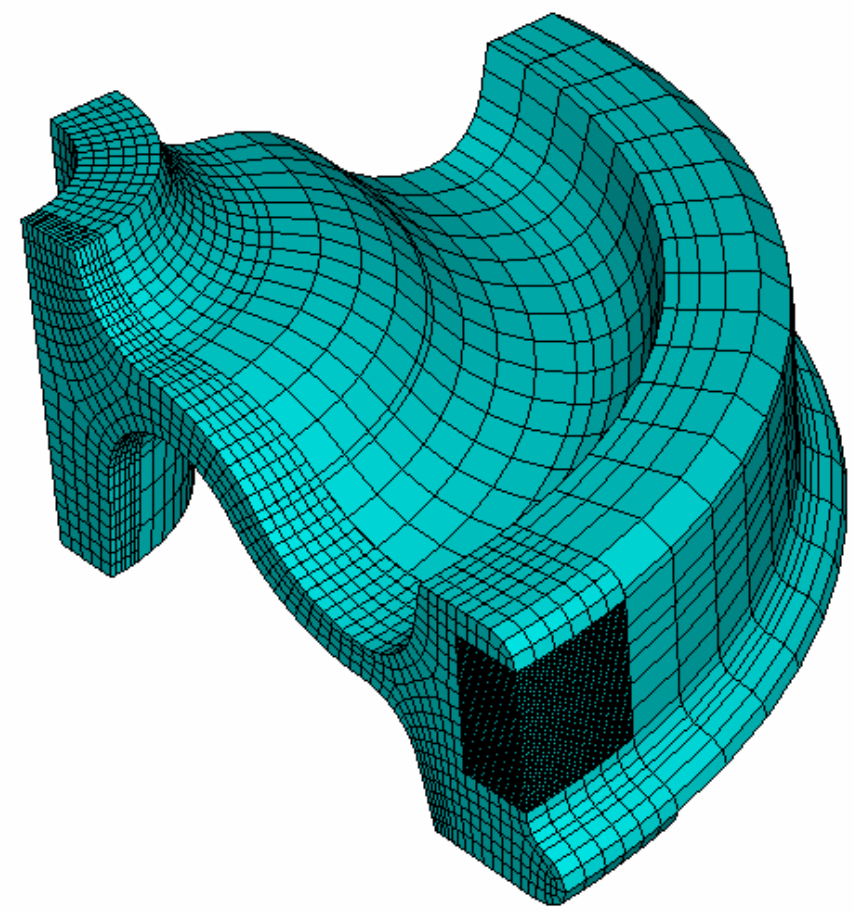

Figure 2. 3D heat treatment/contact model.

Figure 3 shows the refined mesh in the vicinity of the contact load application point. The dense mesh is needed to capture the contact region details accurately.

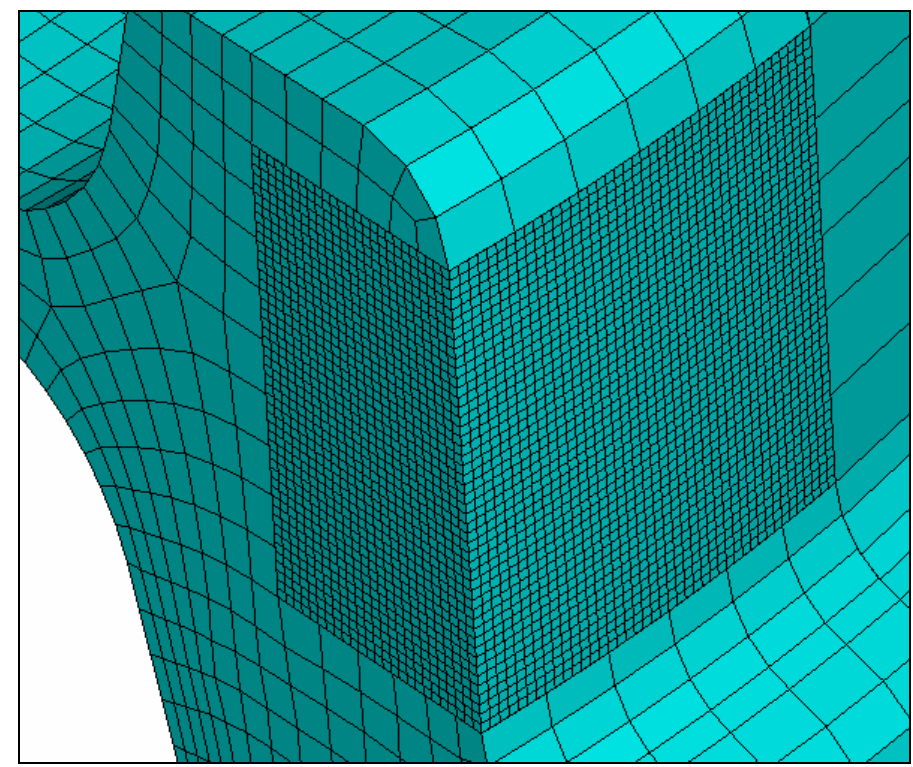

Figure 3. Mesh refinement in wheel rim (detail from Figure 2).
The residual circumferential (hoop) stress is the result of most interest from this analysis. Contours are shown in Figure 4 (for the 2D mesh) and Figure 5 (for the 3D mesh). Contours are in MPa (1 ksi = 6.895 MPa). The 3-dimensional model requires substantially more computational time. However, both the qualitative distribution and quantitative magnitudes are in excellent agreement. Results for transient temperature and other stress components are in comparable agreement between the two models. These checks were used to assess the acceptability of the tied constraint used to connect the regions of dissimilar mesh.

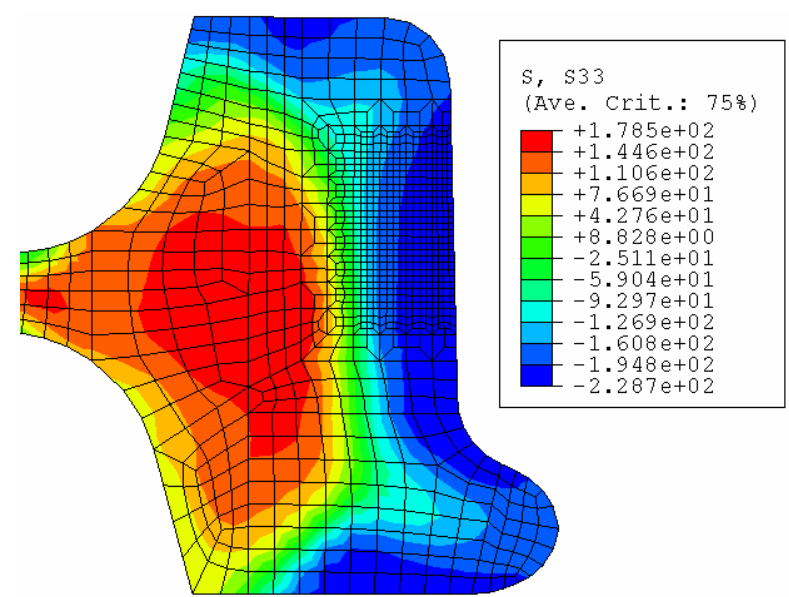

Figure 4. 2D model: hoop stress in wheel rim after simulated manufacturing process. Contours in MPa.

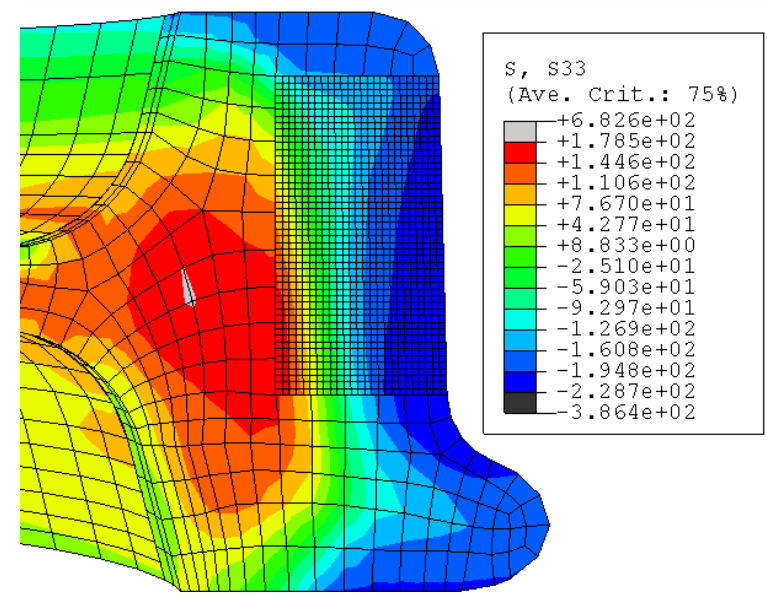

Figure 5. 3D model: hoop stress in wheel rim after simulated manufacturing process. Contours in MPa.

\section{CONTACT SIMULATION: MODELS AND RESULTS}

Contact loading was considered in two ways. First, a rigid "rail" was developed whose geometry approximated that of a 132RE rail crown. Initial results using a rigid representation of the rail resulted in extremely high contact pressure at the wheel/rail interface due to the small size of the of the wheel/rail contact patch. In order to achieve the proper contact pressure distribution and patch size, a deformable rail 
model was required. To minimize model complexity, a "hybrid" deformable rail was created using a small number of deformable 3D elements to represent the rail head coupled to a rigid body which could be used to control the position and displacement of the rail. Symmetry boundary conditions are applied to the wheel/rail model shown in Figure 6.

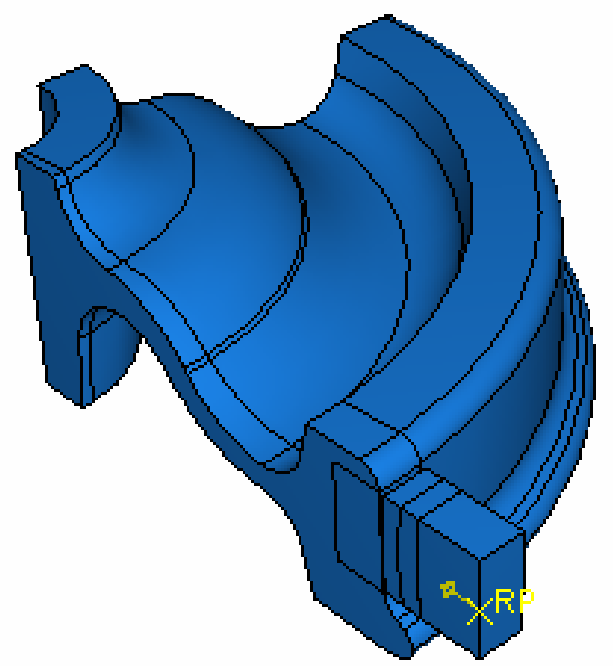

Figure 6. 3D wheel model with deformable rail.

Figure 7 shows the construction of the parts for the deformable rail that loads the wheel. Only the portion of the rail that contacts the wheel is needed to represent an indenter that applied the load.
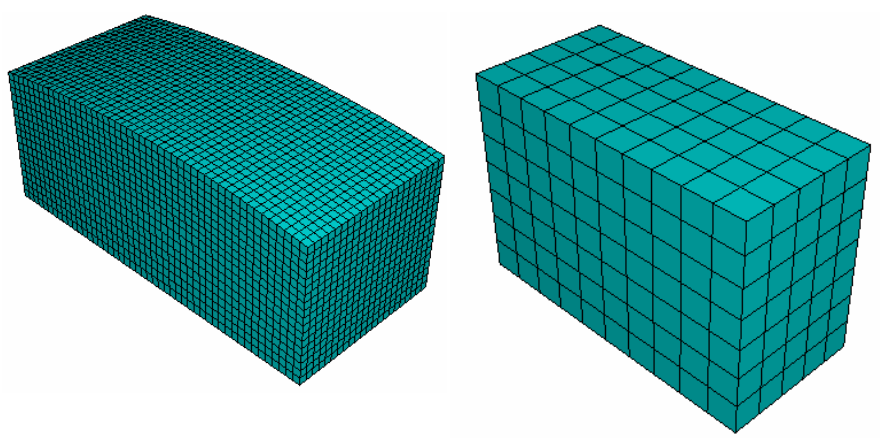

Figure 7. Deformable rail model consists of two parts: deformable tip (left) and rigid support (right).

Reference values and validation for the model were established by considering the classic Hertz elastic contact solution for a static wheel load $(P=17,500 \mathrm{lb}$ or $77.843 \mathrm{kN})$ applied by a 32 in. wheel on a $10 \mathrm{in}$. rail crown. In the analytical solution, the major axis of the contact ellipse is $0.64 \mathrm{~cm}$; the minor axis is $0.468 \mathrm{~cm}$; and the maximum stress is $1243 \mathrm{MPa}$. For the finite element model, the major axis is $0.65 \mathrm{~cm}$; the minor axis is $0.56 \mathrm{~cm}$; and the maximum stress is $1227 \mathrm{MPa}$.
Several material characterizations were investigated. Table 1 lists the five that were compared. A linear, elastic material is included as a reference. Young's modulus is $30,000 \mathrm{ksi}(213,331 \mathrm{MPa})$; the kinematic hardening modulus (if active) is 4,282 ksi (29,526 MPa).

Table 1. Material definitions.

\begin{tabular}{|c|c|c|}
\hline $\begin{array}{c}\text { Materia } \\
\text { I } \\
\text { model }\end{array}$ & Description & $\begin{array}{c}\text { Yield } \\
\text { strength }\end{array}$ \\
\hline $\mathrm{A}$ & Linearly elastic & \multirow{3}{*}{$\begin{array}{c}310 \mathrm{MPa} \\
(45 \mathrm{ksi})\end{array}$} \\
\hline $\mathrm{B}$ & Elastic, perfectly plastic (EPP) & \\
\hline $\mathrm{C}$ & Kinematic hardening $(\mathrm{KH})$ & \\
\hline $\mathrm{D}$ & Elastic, perfectly plastic (EPP) & \multirow{2}{*}{$\begin{array}{c}448 \mathrm{MPa} \\
(65 \mathrm{ksi})\end{array}$} \\
\hline$E$ & Kinematic hardening (KH) & \\
\hline
\end{tabular}

Figure 8 is a schematic plot of the material stress-strain curves. The kinematic hardening $(\mathrm{KH})$ representation with yield strength of $45 \mathrm{ksi}$ is the best approximation of the inelastic behavior of wheel steels. A $65 \mathrm{ksi}$ yield strength can be used to account for some of the effects associated with manufacturing. The corresponding elastic, perfectly plastic (EPP) representations are used to assess analyses based on this simpler, but less realistic characterization.

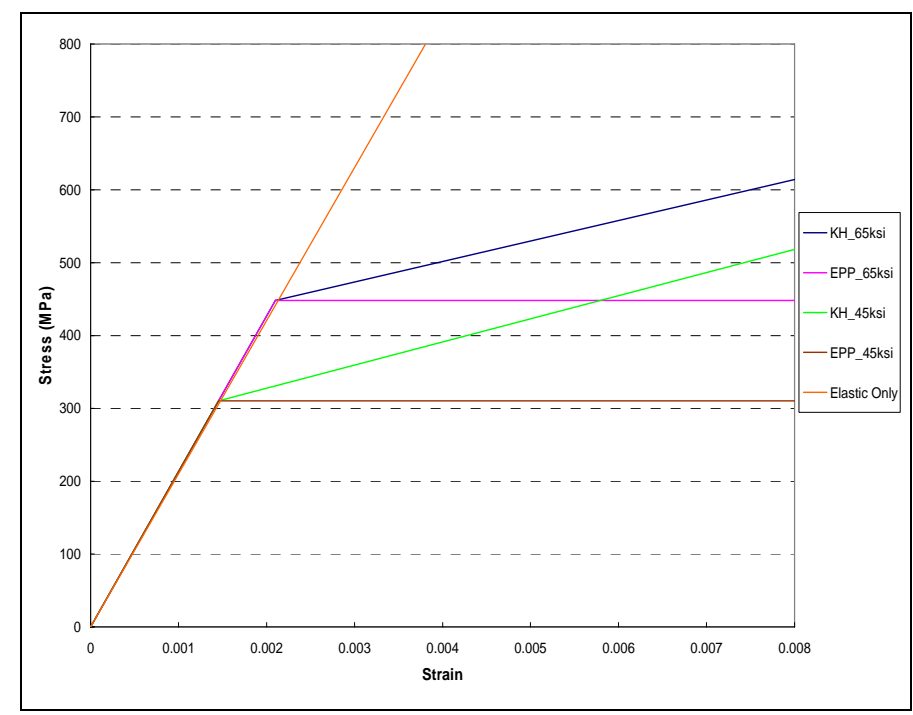

Figure 8. Stress-strain curves of different materials.

Figure 9 shows the distribution of hoop stress through the rim directly under the maximum pressure when the applied static wheel load $P$ is fully applied. The results are consistent with qualitative expectations. Peak stresses are lower at the surface and cross over to tensile values further from the surface when the inelastic effects, lower yield strength or EPP in place of $\mathrm{KH}$, are stronger. 


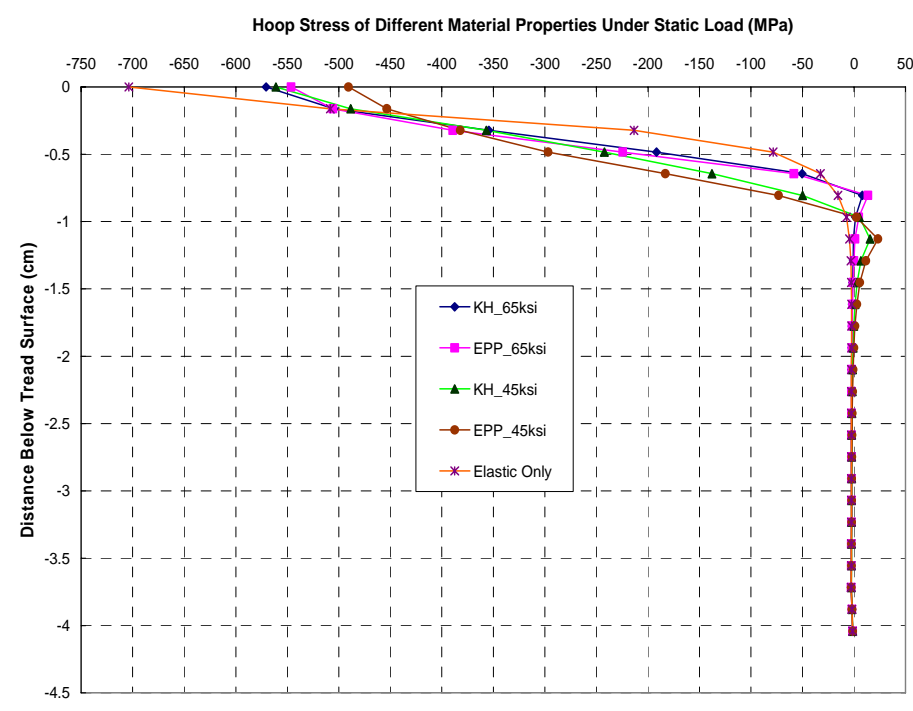

Figure 9. Comparison of hoop stress for different materials at a peak static wheel load $P$.

Figure 10 shows the distribution of hoop stress below the contact point for the case when the applied load is equal to twice the static wheel load, $2 P$. This value is used to assess the influence of dynamic augmentation of the static load. Note that the stress scale is higher than Figure 9. The relative magnitudes are similar, and the tension peaks are shifted down and to higher magnitudes.

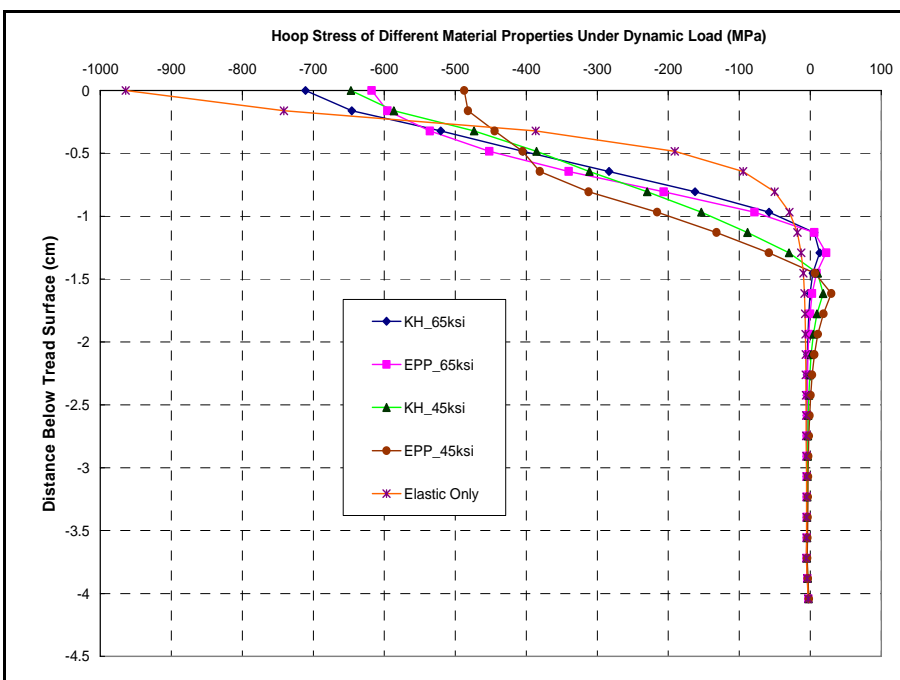

Figure 10. Comparison of hoop stress of different materials for twice static wheel load, $2 P$.

Figure 11 shows the corresponding distributions of residual hoop stress after the load has been removed from the wheel. Note that the hoop stress at the surface is reversed from compressive to tension. However the net residual stress is compression. For the same yield stress, elastic-perfect- plastic materials have bigger tension on the surface than the kinematic hardening materials. This reversal is harmful because the tension promotes the formation of cracks and encourages their growth. Compared with the more than 200 MPa compressive hoop stress in the as-manufactured wheel, the tension caused by contact alone is not overwhelming. Its existence will not be a danger for the wheel. However it could be dangerous when combined with braking.

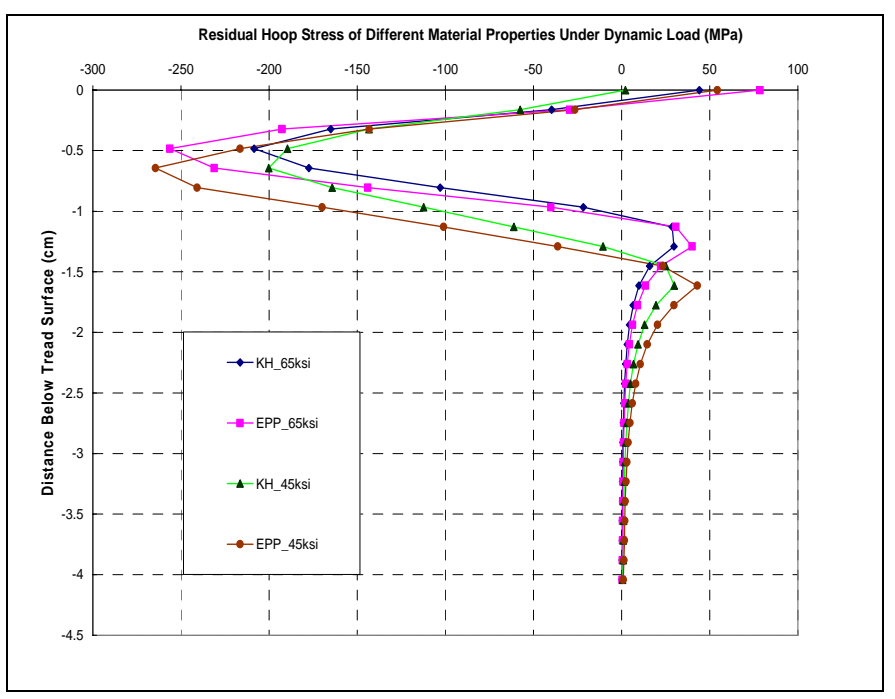

Figure 11. Residual hoop stress for different materials under dynamic load

The plot also shows that for the same yield stress, kinematic hardening materials have less compressive residual stress than elastic-perfect-plastic materials. Yet, the depth of compressive residual stress is the same for kinematic hardening material as for elastic-perfectly-plastic material with the same yield stress. Also note the harder the material is, the smaller residual stress is. The lower the yield stress, the deeper the effect of contact loads.

Table 2 summarizes how material properties affect the level and depth of the residual stress field.

Table 2. Residual Hoop Stress.

\begin{tabular}{|c|c|c|c|c|c|}
\hline $\begin{array}{c}\text { Material } \\
\text { Yield }\end{array}$ & $\begin{array}{c}\text { Max. Compressive } \\
\text { Residual Stress }\end{array}$ & \multicolumn{2}{c|}{$\begin{array}{c}\text { Max. Tensile } \\
\text { Residual Stress }\end{array}$} & $\begin{array}{c}\text { Compression } \\
\text { Zone }\end{array}$ \\
\hline (ksi) & MPa & Depth(cm) & MPa & Depth(cm) & Depth(cm) \\
\hline KH_65 & 209 & 0.48 & 44.1 & 0. & 1.0 \\
\hline EPP_65 & 256 & 0.48 & 78.5 & 0. & 1.0 \\
\hline KH_45 & 200 & 0.64 & 29.9 & 1.61 & 2.35 \\
\hline EPP_45 & 264 & 0.64 & 54.3 & 0. & 2.4 \\
\hline
\end{tabular}

Figure 12 is an alternate representation of these results that shows the interaction of load and material parameters. It shows both the residual hoop component and Von Mises stresses under peak static and dynamic wheel loads. The yield 
stress for the kinematic hardening material is a vertical line as a reference. The traces at the left side show how the higher load raises the maximum residual compression and extends its zone of influence into the wheel rim.

Comparing the Von Mises stress for elastic and kinematic hardening materials indicates how the residual stresses develop. The difference between the elastic and corresponding $\mathrm{KH}$ curves for each load shows how much more redistribution of stress must be done at the higher load. The hoop compression zone ends and the peak tensile stress occur about where the difference in elastic and inelastic ends.

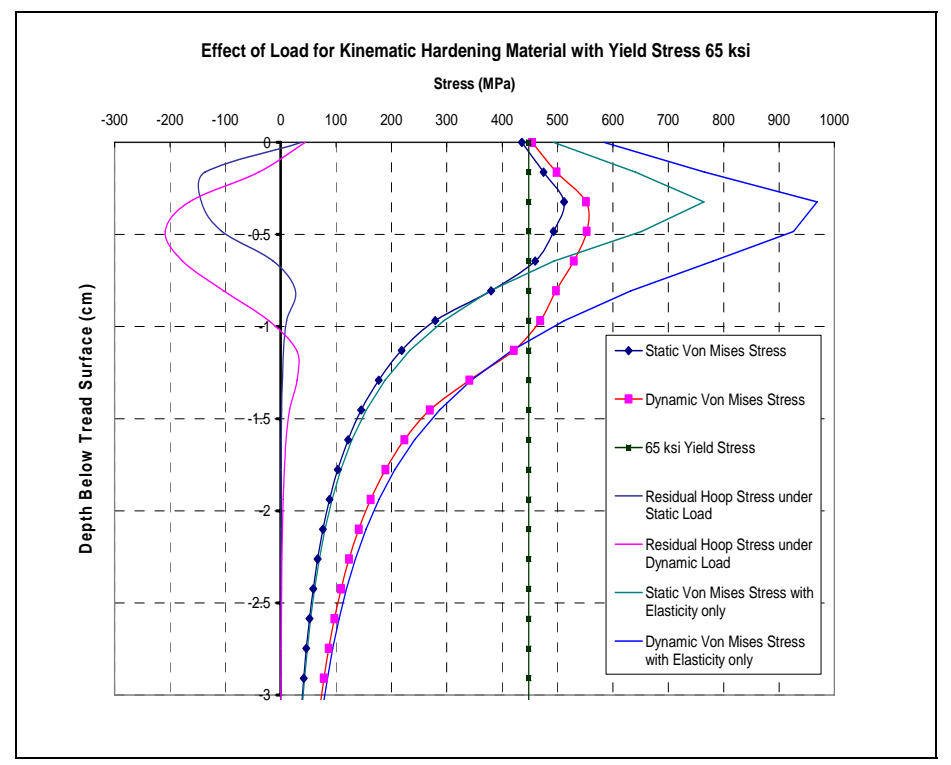

Figure 12. Effect of load for KH_65 ksi material.

Railroad car wheels are exposed to repeated contact loads. When a structure is subjected to cyclic loading in excess of the yield stress of the material, the structure may attain a state in which no further yielding will occur as a result of application of the cyclic load. How the cyclic loads affect the stress distribution in the wheel is another concern of this research. Figure 13 illustrates the load path for two load cycles that were examined in this study. They are intended as prototypes of the concept.

A complete examination of the topic is beyond the scope of this work. Loading starts from A, a state with no initial stress. When the load is big enough, it passes the yield stress point $\mathrm{B}$ and reaches point $\mathrm{C}$. When the load is removed, unloading is elastic,but not from $C$ to $B$ to $A$, but from $C$ linearly to $\mathrm{D}$. If the wheel is reloaded, the path starts from $\mathrm{D}$. If the load is no greater than the first, it will be linearly, elastic along the dash line to point $\mathrm{C}$.

In general, the order and sequence of a spectrum of loads experienced by a wheel could result in many different patterns of residual stress distribution. Measurements of such fields [9] suggest that a consistent configuration evolves from the as-manufactured state after a modest period of service loading. This behavior is typical of a shake down state for the residual field [10]. A rigorous analysis that accounts for kinematic hardening and variation in the location of load application is beyond the scope of this work.

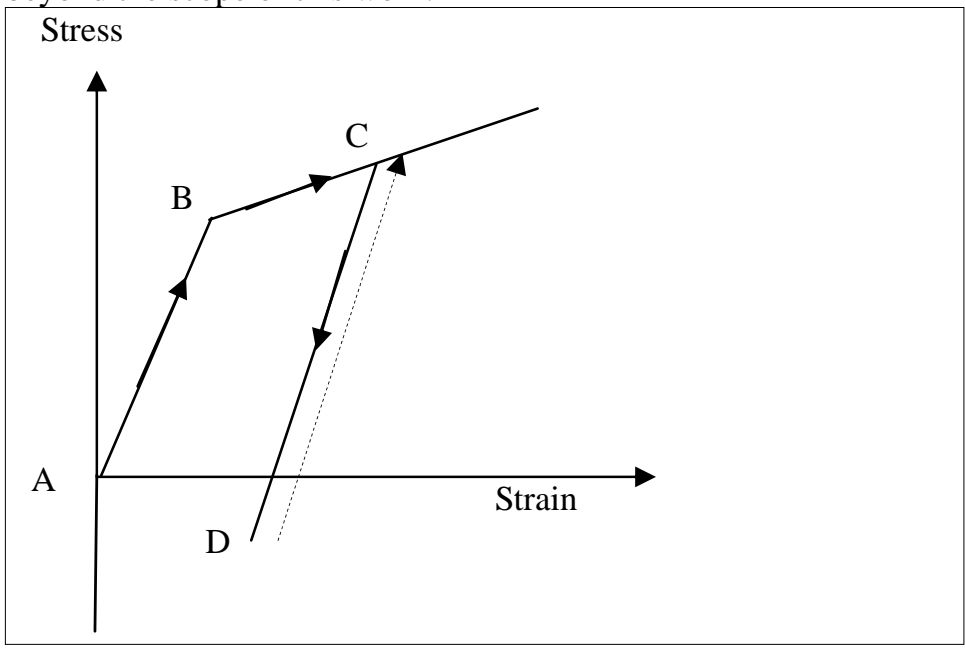

Figure 13. Schematic of load path.

However, a reasonable approximation of the effect of contact loads on a wheel may be represented by a computationally simpler sequence. Figure 14 illustrates the expected result when a static load is repeated at the same point. Repeated applications of the same load are elastic and lead to the same stress field as the first one.

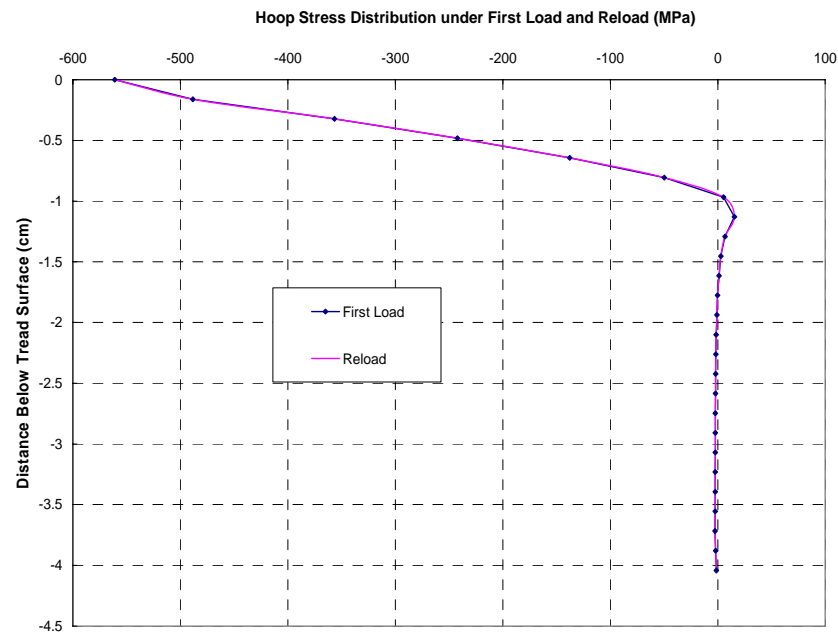

Figure 14. Comparison of hoop stress of first load and reload under static load for $\mathrm{KH} \_45$ ksi.

When the load sequence is varied, the path to the final residual state can be more complicated. However, experience with contact loads that affect a small region near the tread surface suggest that a stable field is dominated by the largest load in the sequence. Figure 15 and Figure 16 show the Von Mises and hoop stress distributions for different load sequences on a wheel of kinematic hardening material with 45 ksi yield stress. 


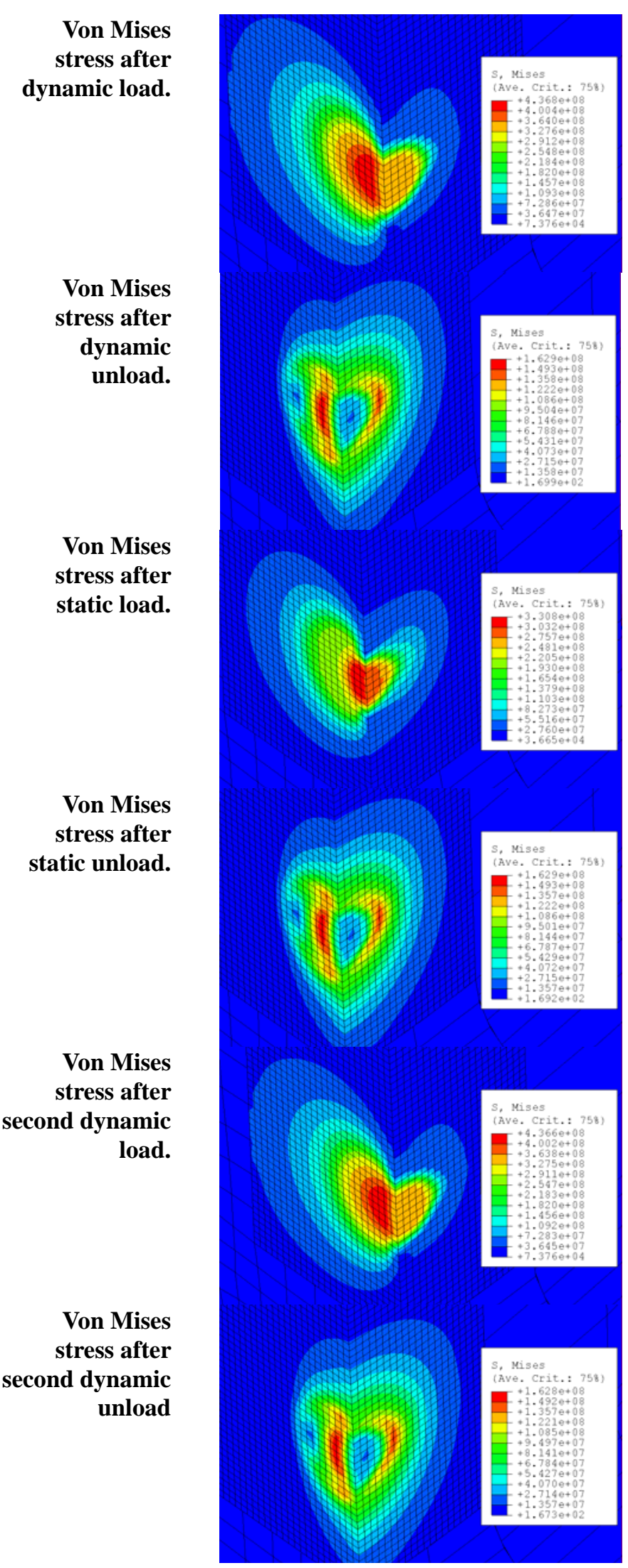

Hoop stress
after dynamic load.

Hoop stress after dynamic unload.

Hoop stress after static load.

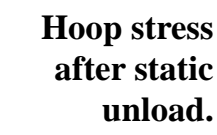

Hoop stress
after second
dynamic load.

Hoop stress after second dynamic unload.
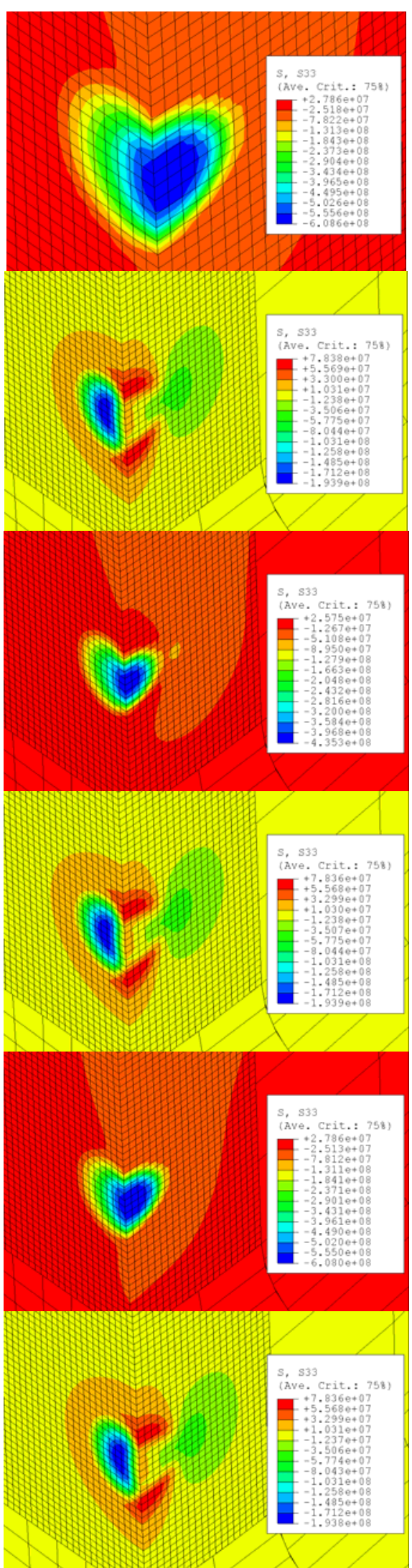

Figure 15. Kinematic hardening material with 45 ksi yield strength under dynamic load-static load-dynamic load sequence 

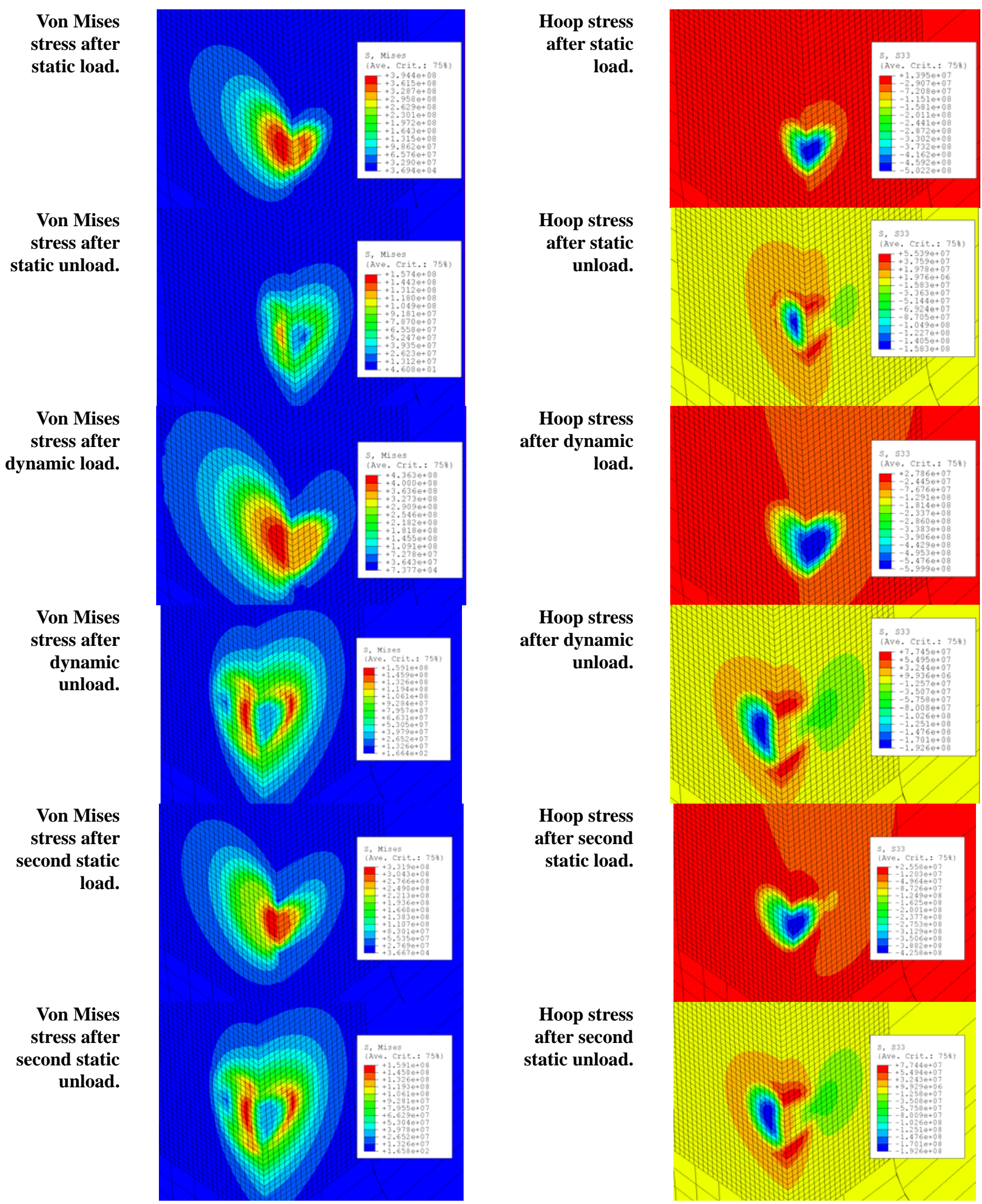

Figure 16. Kinematic hardening material with 45 ksi yield strength under static load-dynamic load-static load sequence. 
The sequence represented in Figure 15 applies and removes a dynamic load, $2 P$, followed by application and removal of a static load, $P$, and finally re-application and removal of the $2 P$ load. Comparison of the first, third and fifth rows in the sequence shows how different the states are when each load is fully applied. In contrast, the second, fourth and sixth rows of results are identical when the loads are removed.

The results in Figure 16 correspond to load and unload of a static, $P$, dynamic, $2 P$ and finally static, $P$ sequence. Again the peak load distributions are different, but the residual stress states are identical after the largest load has been applied and removed.

\section{CONCLUSIONS}

This paper has presented the extension of previous studies aimed at understanding the residual stress distribution in asmanufactured railroad wheels. In order to address loading conditions which are not axially symmetric, a manufacturing simulation has been conducted with a 3-dimensional model. Results from the 2- and 3-dimensional models have been shown to be comparable. This agreement allows the manufacturing model to be integrated with other loading conditions such as contact.

Manufacturing simulations using the 2D, axisymmetric model execute in about 50 minutes on a $2.8 \mathrm{GHz}$ PC. Contact load simulations with the $3 \mathrm{D}$ model ran for about 60 hours on the same machine.

An analysis methodology to estimate residual stresses in the wheel rim due to simulated wheel/rail contact was illustrated with a prototype calculation. A deformable representation of a portion of the rail was needed to capture the contact pressure distribution and patch size of the contact zone. The indenting rail was modeled with two regions. Load is applied to a rigid part. The second region is deformable. It acts to distribute the load as it forms a contact zone interacting with the surface of the wheel model.

Initial manufacturing stresses were not considered in order to confirm the validity of the contact model. Previous work which attempted to develop residual stress estimates in wheels due to manufacturing and service conditions relied on a very simplified material model and crude means of accounting for contact pressure. An investigation of more realistic material models has also been conducted. While the as-manufactured residual stresses have not been included in the development work presented here, future efforts will concentrate on integrating the manufacturing, contact and thermal effects in a single model. Such a model is envisioned to form the basis for an analysis procedure for consideration as a replacement for the current AAR S-660 wheel design standard.

\section{REFERENCES}

[1]Gordon, J., "Estimation of Residual Stresses in Railroad Car Wheels Resulting from Manufacture and Service Loading,” MS Thesis, Tufts University, Medford, MA, February 1998.

[2]Gordon J. and A. B. Perlman, "Estimation of residual stresses in railroad commuter car wheels following manufacture," Proc. International Mechanical Engineering Congress and Exhibition, ASME RTD Vol. 15, 13 - 18 (1998).

[3]Gordon J., J.A. Jones and A.B. Perlman, "Estimation of service-induced residual stresses in railroad commuter car wheels," Proc. International Mechanical Engineering Congress and Exhibition, ASME RTD Vol. 15, 25 - 32 (1998).

[4]Gordon, J. and A. Benjamin Perlman, "Effects of Service Conditions on the As-Manufactured Residual Stress Distribution in Commuter Car Wheels." Proc. $13^{\text {th }}$ International Wheelset Congress, Rome, Italy, September 17-21, 2001.

[5]Gordon, J. and A. Benjamin Perlman, "Effects of Wear and Service Conditions on Residual Stresses in Commuter Car Wheels," Proc. $14^{\text {th }}$ International Wheelset Congress, Orlando, FL, November 17-21, 2004.

[6]Talamini, B., J. Gordon and A. Benjamin Perlman, "Development of a Standard for New Passenger Wheel Designs,” Proc. International Mechanical Engineering Congress and Exhibition, ASME RTD (2006).

[7]Liu, S., Finite Element Analysis of Residual Stresses in Railroad Car Wheel," MS Thesis, Tufts University, Medford, MA, February 2006.

[8]Abaqus/Standard User's Manual, Volume I and II (version 6.5-1). Hibbitt, Karlsson and Sorenson, Inc., Warwick, RI, 2004.

[9]Gnäupel-Herold, T., P.C. Brand, and H.J. Prask, "Neutron Diffraction Investigation of Residual Stresses in Transverse/Oblique Rail Slices Subjected to Different Grinding Strategies,” NISTIR 6305. National Institute of Standards and Technology, Gaithersburg, MD, 1999.

[10]J. Gordon, A.B. Perlman and O. Orringer, "Effect of grinding strategy on residual stress in the rail head," in Rail Quality and Maintenance for Modern Railway Operation, (J.J. Kalker, D.F. Cannon, and O. Orringer, ed.), Kluwer Academic Publishers, Dordrecht, The Netherlands, 297-306 (1993). 